\title{
Online estimation of stator resistance of an induction motor for speed control applications
}

\author{
L. Umanand \\ S.R. Bhat
}

Indexing terms: Induction motors, Stator resistance, Speed control, Flux estimation

\begin{abstract}
Speed control of induction motors requires the accurate estimation of the fluxes in the motor. But the flux estimate, when estimated from the stator circuit variables, is dependent on the stator resistance of the induction motor. As a consequence the flux estimate is prone to errors due to variations in the stator resistance, especially at low stator frequencies. A scheme is presented in this paper for an online estimation of the stator resistance under steady state operating conditions, using variables that can be measured from the terminals of the motor alone. The scheme is based on estimating the steady-state magnitudes of the stator and rotor flux space phasors using the reactive power. An analysis of the effect of the stator resistance variations on the flux estimate is presented. A simulation of a rotor field oriented speed control of a VSI-fed induction motor using stator circuit variables is performed incorporating the online stator resistance estimation strategy.
\end{abstract}

\section{Introduction}

The speed control of induction motors can be divided into two distinct categories depending on the type of dynamics required; (i) scalar control [1] and (ii) vector control $[2,3]$. Scalar control involves maintaining the flux magnitude in the machine constant. The $V / f$ controllers which use voltage source inverters to obtain variable voltage-variable frequency control by pulse width modulation strategies, fall under this category. Though this control method has the advantage of simplicity and low cost, its main drawback is the poor torque dynamics. In the case of vector controllers, the current space vector is controlled both in magnitude and position to achieve decoupled control of the torque-producing and the fiuxproducing components of the stator current space phasor. This allows good transient response of the motor. To achieve decoupled control, either the stator flux, airgap flux or the rotor flux should be known both in magnitude and position. This is usually obtained either by using flux sensors (direct field-oriented control) or by estimators using measurable states of the induction motor (indirect field-oriented control). The implementation of direct field-oriented control requires the measurement or calcu- lation of the flux space phasor both in magnitude and position. Sensing devices placed in the airgap of the machine will determine the airgap flux space phasor. The airgap flux can be sensed either by using Hall effect devices or by using stator search (sense) coils. But both techniques suffer from the common disadvantage that a specially constructed induction motor is required. Hall sensors are very sensitive to temperature and mechanical vibration, and also the flux signal is distorted by large slot harmonics that cannot be filtered effectively because their frequency varies with motor speed. In the case of stator search coils that sense the rate of change of airgap flux, induced voltage in the search coils is proportional to the rate of change of flux. At low speeds below about $1 \mathrm{~Hz}$, the induced voltage will be significantly low which would give rise to inaccurate flux sensing owing to the presence of noise and disturbances in a practical system. On the other hand, indirect sensing of flux space phasors gives a more versatile drive system that can be used with standard commercial motors, but this approach would generally result in a more complex control system. In the indirect method of field orientation, the flux space phasor is estimated from the motor model. As a consequence, all indirect methods are sensitive to variations in some machine parameter.

Both in the case of scalar $V / f$ control and the vector controllers (stator flux vector control and rotor flux vector control using stator variables), the fluxes will have to be estimated. The estimation of the fluxes is dependent on the machine parameters of the induction motor. Errors occur in the flux estimate due to variations in the inductive parameters of the motor due to saturation effects of the magnetic material involved and due to variations in the stator resistance which occur mainly because of temperature changes. This would cause poor regulation of the flux in the case of the scalar control and deterioration in the torque dynamics in the case of vector control. The effects of the variations of the inductive parameters of the motor are considered in References 3 and 4. In this paper, the motor shall be considered to be operating in the linear region of the $\boldsymbol{E}-\boldsymbol{H}$ characteristics where the machine inductances can be assumed as constants. This paper will focus on the effect of the stator resistance variations and develop a scheme to estimate it. However, the effect of the uncertainty in the magnetising inductance of the induction motor on the stator resistance estimation scheme is also discussed.

Techniques like embedding a thermal transducer in the stator winding have been used to compensate for the variations in the stator resistance due to temperature. But it is desirable to have a scheme which is not dependent on special motor constructions. In this respect, Reference 1 discusses a $V / f$ control scheme wherein the 
reactive power is used to estimate the airgap flux independent of the motor resistances. In Reference 5 the saturation induced harmonics are used to indicate errors in the stator resistance due to temperature. In Reference 7, multiple current measurements in a voltage pulse are performed and are used to evaluate the stator resistance. In this paper, the stator resistance is estimated using the two-axis induction motor model. The stator resistance is viewed as a function of the stator voltages, currents and stator flux magnitude, which is obtained using the reactive power of the motor.

\section{Induction motor model}

The model of the induction motor $[2,3]$ in the stator (or stationary) reference frame is given by

$$
\begin{aligned}
& V_{s \alpha}=R_{s} i_{s \alpha}+\frac{d \psi_{s \alpha}}{d t} \\
& V_{s \beta}=R_{s} i_{s \beta}+\frac{d \psi_{s \beta}}{d} \\
& \mathbf{0}=R_{r} i_{r \alpha}+\frac{}{d t}+\omega_{m} \psi_{r \beta} \\
& 0=R_{r} i_{r \beta}+\frac{d \psi_{r \beta}}{d t}-\omega_{m} \psi_{r \alpha} \\
& T_{d}=T_{L}+\frac{J d w,}{P}+\frac{B}{P} w,
\end{aligned}
$$

where

$V_{s \alpha}, V_{s \beta}$ are the a-axis and $\beta$-axis stator voltages in the stator reference frame. $i_{s \alpha}, i_{s \beta}$ are the corresponding stator currents in the stator reference frame. $\psi_{s \alpha}, \psi_{s \beta}$ are the stator fluxes and $\psi_{r a}, \psi_{r \beta}$ are the rotor fluxes in the stator reference frame

$R_{\mathrm{s}}=$ stator resistance per phase

$R_{r}=$ rotor resistance per phase

$T_{d}=$ motor drive torque or the electromagnetic torque

$T_{L}=$ load torque

$J=$ equivalent inertia seen by the rotor

$\mathrm{B}=$ frictional coefficient

$\mathrm{p}=$ number of pole pairs

$\boldsymbol{w},=$ electrical rotor frequency which is $\mathrm{p}$ times the shaft speed.

The stator and the rotor fluxes are defined as

$$
\begin{aligned}
& \psi_{s \alpha}=L_{s s} i_{s \alpha}+M i_{r \alpha} \\
& \psi_{s \beta}=L_{s s} i_{s \beta}+M i_{r \beta} \\
& \psi_{r \alpha}=M i_{s \alpha}+L_{r r} i_{r \alpha} \\
& \psi_{r \beta}=M i_{s \beta}+L_{r r} i_{r \beta}
\end{aligned}
$$

where

$i_{r \alpha}, i_{r \beta}$ are the rotor currents in the stator reference frame

$M=$ three-phase equivalent magnetising inductance of the induction motor

$L_{s s}=L_{\sigma s}+M ; L_{\sigma s}$ is the stator leakage inductance; $L_{s s}$ is the stator self inductance

$L_{r r}=L_{\sigma r}+\mathrm{M} ; L_{\sigma r}$ is the rotor leakage inductance; $L_{r r}$ is the rotor self inductance referred to the stator.

\section{Effect of stator resistance variations}

The effect of stator resistance variations are considered with respect to the stator flux scalar and vector control of induction motors and the rotor flux vector control, where the rotor flux space phasor is estimated from the stator circuit variables.

3.1 Stator flux scalar control

The stator flux is estimated using eqns. 1 and 2 of the induction motor model as in Reference 5.

$$
\begin{aligned}
& \frac{d \psi_{s x}}{d t}=\left(V_{s x}-R_{s} i_{s \alpha}\right) \\
& \frac{d \psi_{s \beta}}{d t}=\left(V_{s \beta}-R_{s} i_{s \beta}\right)
\end{aligned}
$$

It is evident from eqns. 10 and 11 that the stator flux is dependent on the stator resistance of the induction motor. In the discussions to follow, variables with a * superscript will represent the actual values in the induction motor and the variables without a ${ }^{*}$ superscript will denote the model values which are used for control. Using eqns. 10 and 11 , the actual values of the stator fluxes in the motor are given by

$$
\begin{aligned}
& \frac{d \psi_{s \alpha}^{*}}{d t}=\left(V_{s \alpha}^{*}-R_{s}^{*} i_{s \alpha}^{*}\right) \\
& \frac{d \psi_{s \beta}^{*}}{d t}=\left(V_{s \beta}^{*}-R_{s}^{*} i_{s \beta}^{*}\right)
\end{aligned}
$$

The stator voltages and currents are measurable variables and so their values in the model and the machine are the same. Hence one can apply the following constraints to eqns. $10-13$ :

Constraint $I: V_{s \alpha}=V_{s \alpha}^{*} ; i_{s \alpha}=$ if

Constraint 2: $V_{s \beta}=V_{s \beta}^{*} ; i_{s \beta}=i f$,

Defining the error in the stator fluxes as

$$
\begin{aligned}
& e_{s \alpha}=\psi_{s \alpha}^{*}-\psi_{s \alpha} \\
& e_{s \beta}=\psi_{s \beta}^{*}-\psi_{s \beta}
\end{aligned}
$$

and the error in the stator resistance as

$$
\mathrm{AR},=R_{s}^{*}-R_{s}
$$

the error dynamics are given by

$$
\begin{aligned}
& \frac{d e_{s \alpha}}{d t}=-\Delta R_{s} i_{s \alpha} \\
& \frac{d e_{s \beta}}{d t}=-\Delta R_{s} i_{s \beta}
\end{aligned}
$$

As the intention in scalar flux control applications is to maintain the stator flux constant at steady-state, the effect of the stator resistance variations can be studied under steady-state conditions, i.e. when the stator currents are sinusoidal. Therefore, applying the following constraints on eqns. 14 and 15 :

Constraint 3: $i_{s \alpha}=\left|i_{s}\right| \cos \left(\omega_{s} \mathrm{t}\right)$

Constraint $4: i_{s \beta}=\left|i_{s}\right| \sin (w, \mathrm{t})$ 
where $\omega_{s}$ is the rotating frequency of the stator current space phasor.

This results in the following error equations:

$$
\begin{aligned}
& e_{s \alpha}=-\left(\frac{\Delta R_{s}}{\omega_{s}}\right) i_{s \beta} \\
& e_{s \beta}=\left(\frac{\Delta R_{s}}{\omega_{s}}\right) i_{s \alpha}
\end{aligned}
$$

From eqns. 16 and 17 , it is evident that at high stator frequencies, $\omega_{\mathrm{s}}$ the error due to variations in the stator resistance is negligible, but at low stator frequencies the errors are very significant which results in poor flux regulation.

\subsection{Stator flux vector control}

In stator flux vector control, $d-q$ axes $(\alpha-\beta$ axes in the stator reference frame) of the induction motor are in the synchronously rotating stator flux reference frame wherein the d-axis circuit is aligned along the stator flux space phasor. Therefore, in the stator flux vector control, the stator flux has to be estimated both in magnitude and position. Using eqns. 10 and 11 the magnitude $\psi$, and the position $\rho_{s}$ of the stator flux space phasor are given by

$$
\begin{aligned}
& \psi_{s}=\sqrt{ }\left(\psi_{s \alpha}^{2}+\psi_{s \beta}^{2}\right) \\
& \rho_{s}=\operatorname{atan}\left(\frac{\psi_{s \beta}}{\psi_{s \alpha}}\right)=\operatorname{acos}\left(\frac{\psi_{s \alpha}}{\psi_{s}}\right)
\end{aligned}
$$

The error dynamics are given by eqns. 14 and 15 where it is evident that the errors are dependent on the stator resistance variations. The errors in the stator flux space phasor estimate would result in field disorientation which would lead to poor torque dynamics. It is important to note at this point that the error dynamics given in eqns. 14 and 15 show no error decaying mechanism. Therefore one has to use a corrective prediction error term $[6,7]$ in eqns. 10 and 11 to obtain a stable stator flux estimate.

\subsection{Rotor flux vector control using stator circuit} variables

In rotor flux vector control, the $\boldsymbol{d}-\boldsymbol{q}$ axes of the induction motor are in the synchronously rotating rotor flux reference frame wherein the d-axes circuit is aligned along the rotor flux space phasor. Using eqns. 6-9, the rotor fluxes can be expressed in terms of the stator fluxes $[7,8,9]$,

$$
\begin{aligned}
& \frac{d \psi_{r \alpha}}{d t}=-\left(\frac{L_{\sigma}}{v_{r}}\right) \frac{d i_{s \alpha}}{d t}+\left(\frac{1}{v_{r}}\right) \frac{d \psi_{s \alpha}}{d t} \\
& \frac{d \psi_{r \beta}}{d t}=-\left(\frac{L_{\sigma}}{v_{r}}\right) \frac{d i_{s \beta}}{d t}+\left(\frac{1}{v_{r}}\right) \frac{d \psi_{s \beta}}{d t}
\end{aligned}
$$

where

$$
\begin{aligned}
v_{r} & =M / L_{r r} \\
L_{a} & =\left(L_{s s} L_{r r}-M^{2}\right) / L_{r r}
\end{aligned}
$$

and the stator fluxes are obtained from eqns. 10 and 11 .

From eqns. 20 and 21, the rotor flux space phasor is given in magnitude $\psi_{r}$ and position $\rho_{r}$ as

$$
\begin{aligned}
& \psi_{r}=\sqrt{ }\left(\psi_{r \alpha}^{2}+\psi_{r \beta}^{2}\right) \\
& \rho_{r}=\operatorname{atan}\left(\frac{\psi_{r \beta}}{\psi_{r \alpha}}\right)=\operatorname{acos}\left(\frac{\psi_{r a}}{\psi_{r}}\right)
\end{aligned}
$$

Using eqns. 10,11, 20 and 21 , the actual values of the rotor fluxes in the motor are given by

$$
\begin{aligned}
& \frac{d \psi_{r \alpha}^{*}}{d t}=-\left(\frac{L_{\sigma}}{v_{r}}\right) \frac{d i_{s \alpha}^{*}}{d t}+\left(\frac{1}{v_{r}}\right)\left(V_{s \alpha}^{*}-R_{s}^{*} i_{s \alpha}^{*}\right) \\
& \frac{d \psi_{r \beta}^{*}}{d t}=-\left(\frac{L_{\sigma}}{v_{r}}\right) \frac{d i_{s \beta}^{*}}{d t}+\left(\frac{1}{v_{r}}\right)\left(V_{s \beta}^{*}-R_{s}^{*} i_{s \beta}^{*}\right)
\end{aligned}
$$

The values of the stator voltages and currents in the model and the machine are the same. Hence, applying the constraints 1 and 2 to eqns. 20,21, 24 and 25 and defining the error in the rotor fluxes as

$$
\begin{aligned}
& e_{r \alpha}=\psi_{r \alpha}^{*}-\psi_{r \alpha} \\
& e_{r \beta}=\psi_{r \beta}^{*}-\psi_{r \beta}
\end{aligned}
$$

and the error in stator resistance as

$$
\Delta R_{\mathrm{s}}=R_{s}^{*}-R_{\mathrm{s}}
$$

the error dynamics are given by

$$
\begin{aligned}
& \frac{d e_{r \alpha}}{d t}=-\left(\frac{1}{v_{r}}\right) \Delta R_{s} i_{s z} \\
& \frac{d e_{r \beta}}{d t}=-\left(\frac{1}{v_{r}}\right) \Delta R_{s} i_{s \beta}
\end{aligned}
$$

From eqns. 26 and 27, it is evident that any detuning in the value of the stator resistance causes an error in the value of the rotor flux estimate. This would cause the model rotor field to be disoriented with respect to the actual rotor field and cause deterioration in the torque dynamics. Applying the sinusoidal current constraints 3 and 4 to the stator currents and using them in eqns. 26 and 27 , one obtains

$$
\begin{aligned}
& e_{r \alpha}=-a 1 \mathrm{AR} \mathrm{i}_{\mathrm{s} \beta} \\
& e_{r \beta}=\mathrm{a}, \Delta R_{\mathrm{s}} i_{s \alpha}
\end{aligned}
$$

where

$$
a_{1}=1 /\left(v_{r} \omega_{s}\right)
$$

From eqns. 28 and 29, it is evident that the detuning in $R_{\mathrm{s}}$ causes significant rotor field disorientation especially at low stator frequencies, although at high stator frequencies the errors are negligible.

\section{Estimation of stator resistance}

It is evident from the discussion in Section 3 that the estimation of the actual value of the stator resistance is important especially at low stator frequencies. In this Section, the estimation of the actual value of the motor stator resistance from terminal variables is discussed. As the rate of variation of the stator resistance is low compared to the electrical time constants involved, the sinusoidal current constraints 3 and 4 are valid. Similar sinusoidal constraints apply to the stator fluxes. Application of these constraints to eqns. 1 and 2 results in

$$
\begin{aligned}
& V_{s \alpha}=R_{s} i_{s \alpha}-\omega_{s} \psi_{s \beta} \\
& V_{s \beta}=R_{s} i_{s \beta}+\omega_{s} \psi_{s \alpha}
\end{aligned}
$$

Eqns. 30 and 31 can be combined to give

$$
V_{s}^{2}=R_{s}^{2} i_{s}^{2}+\omega_{s}^{2} \psi_{s}^{2}+3 \omega_{s} T_{d} R_{s}
$$


where

$$
\begin{aligned}
V_{s}^{2}= & V_{s \alpha}^{2}+V_{s \beta}^{2} \\
i_{s}^{2}= & i_{s \alpha}^{2}+i_{s \beta}^{2} \\
T_{d}= & (2 / 3) M\left(\psi_{s \alpha} i_{s B}-\psi_{s \beta} i_{s a}\right) \text { which is the electromag- } \\
& \text { netic torque }
\end{aligned}
$$

Eqn. 32 is a quadratic expression which has the solution given by

$$
R_{s}=\frac{-3 \omega_{s} T_{d}+\sqrt{ }\left(9 \omega_{s}^{2} T_{d}^{2}+4 \mathrm{Vf} i_{s}^{2}-4 \omega_{s}^{2} \psi_{s}^{2} i_{s}^{2}\right)}{2 i_{s}^{2}}
$$

Eqn. 33 is the estimate for the motor stator resistance. In eqn. 33, $\boldsymbol{V}_{s}^{2}$ and $\boldsymbol{i}_{\boldsymbol{s}}^{2}$ are measurable quantities and hence they represent the actual values in the motor. The stator frequency $\omega_{s}$ is an input to the motor and therefore it is obtained from the model itself. The electromagnetic torque $T_{d}$ and the stator flux magnitude $\psi_{s}$ remain to be evaluated and are discussed in the following subsection.

\subsection{Evaluation of the electromagnetic torque, $T_{d}^{*}$}

The electromagnetic torque $[2,3]$ in an arbitrary reference frame is given by

$$
T_{d}^{*}=\left(\frac{2}{3} p\right)\left(\psi_{s d}^{*} i_{s q}^{*}-\psi_{s q}^{*} i_{s d}^{*}\right)
$$

where $\psi_{s d}^{*}$ and $\psi_{s q}^{*}$ are the actual values of the direct and the quadrature axes components of $\psi_{s}^{*}$ in an arbitrary reference frame, and $\boldsymbol{i}_{\boldsymbol{s} d}^{*}$ and $\boldsymbol{i}_{s q}^{*}$ are the actual values of the direct and the quadrature axes components of $i_{s}^{*}$ in the arbitrary reference frame.

As the electromagnetic torque is invariant under coordinate transformation, it can be evaluated in any convenient reference frame. In this Section, evaluating \& in the rotor flux reference frame allows only terminal variables to be used in its evaluation. Therefore, using eqns. (6-9) in eqn. 34 results in

$$
T_{d}^{*}=\left(\frac{2}{3} p\right)\left(\frac{M}{L_{r r}}\right)\left(\psi_{r}^{*} i_{s q r}^{*}\right)
$$

where

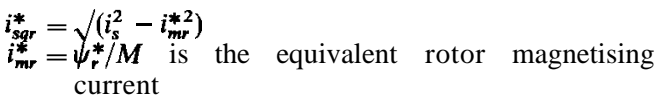

The evaluation of $\psi_{s}^{*}$ and $\psi_{r}^{*}$ is discussed in the following subsection.

\subsection{Evaluation of $\psi_{s}^{*}$ and $\psi_{r}^{*}$}

The stator and the rotor flux space phasor magnitudes are determined from the model of the induction motor using eqns. (1-4). Applying the constraints 3 and $\mathbf{4}$ on the stator currents and similar sinusoidal constraints on the rotor currents which are phase shifted by an angle $\theta_{s r}$ with respect to the stator currents, one obtains

$$
\begin{aligned}
\psi_{s}^{* 2}= & \left(\frac{2 L_{r r} L_{s s}-M^{2}}{L_{r r}}\right)\left(\frac{2 P_{r}}{\omega_{s}}\right) \\
& -\left(\frac{L_{s s}}{L_{r r}}\right)\left(L_{r r} L_{s s}-M^{2}\right) i_{s}^{2} \\
\psi_{r}^{*}= & \sqrt{\left[\frac{L_{r r}}{\omega_{s}}\left(2 P_{r}\right)-\left(L_{r r} L_{s s}-M^{2}\right) i_{s}^{2}\right]}
\end{aligned}
$$

where $P_{r}$ is the reactive power which is given by

$$
P_{r}=\frac{V_{s \beta} i_{s \alpha}-V_{s \alpha} i_{s \beta}}{2}
$$

The stator flux evaluated using eqn. $\mathbf{3 6}$ is then used in eqn. $\mathbf{3 3}$ to estimate the stator resistance. The electromagnetic torque is evaluated by substituting eqn. 37 in eqn. 35.

\subsection{Evaluation of reactive power, $P$,}

The evaluation of the reactive power requires some discussion. One should note that $V_{s a}$ and $V_{s \beta}$ are pulse width modulated switching quantities and hence would require filtering. But filtering would change the phase relationship between the phase voltages and currents which is undesirable. As the reactive power is invariant under coordinate transformations, the two-phase voltages should be transformed to the synchronously rotating reference frame with the axis aligned along the stator current space phasor as follows:

$$
V_{s d(i s)}+j V_{s q(i s)}=\left(V_{s \alpha}+j V_{s \beta}\right) e^{-j \gamma}
$$

where $\boldsymbol{V}_{s d(i s)}$ and $\boldsymbol{V}_{s q(i s)}$ are the $\mathrm{d}$ and $q$ components of the voltage space phasors with respect to a reference frame wherein the d-axis is aligned along the stator current space phasor. The position of the stator current space phasor $\gamma$ is given by

$$
\gamma=\operatorname{atan}\left(\frac{i_{s \beta}}{i_{s \alpha}}\right)
$$

Evaluation of the reactive power is now equivalent to evaluating $\left(V_{s q(i s)}\left|i_{s}\right|\right) / 2$. Using a filter in this reference frame will clearly not affect the phase relationships between the voltages and currents.

\subsection{Stator resistance estimation algorithm}

The block schematic of the stator resistance estimator is shown in Fig. 1. The algorithm consists of the following steps:

Step 1: Evaluate the reactive power from the measured terminal variables as discussed in Section 4.3.

Step 2: Evaluate the values of the stator and rotor flux space phasor magnitudes using eqns. $\mathbf{3 6}$ and $\mathbf{3 7}$.

Step 3: Evaluate the actual value of the drive torque $T_{d}^{*}$ using eqn. 35 .

Step 4: Estimate the actual value of the stator resistance from eqn. 33.

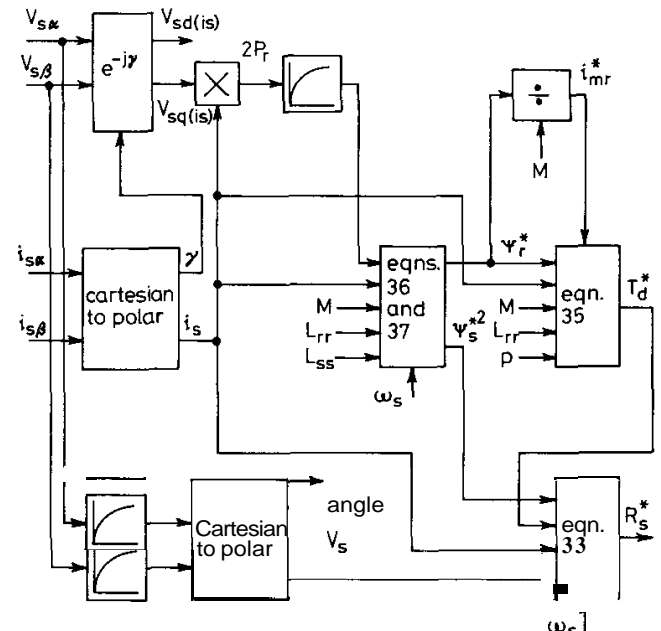

Fig. 1 Block schematic of the stator resistance estimator

\section{Effect on stator resistance estimation due to uncertainties in the inductive parameters of} the motor

It is evident from the stator resistance estimate eqn. $\mathbf{3 3}$ that uncertainties in the inductive parameters introduce errors in the stator resistance estimate. Clearly, the only 
two components of eqn. $\mathbf{3 3}$ that contribute to the errors in the stator resistance estimate due to variations in the inductive parameters of the motor, are the drive torque and the stator flux. To simplify the foregoing analysis, only the uncertainty in the magnetising inductance $\boldsymbol{M}$

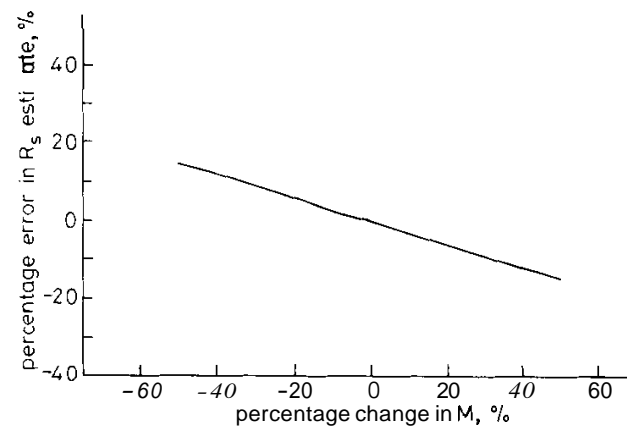

Fig. 2 Error in the stator resistance estimation due to uncertainties in the magnetising inductance $M \quad i_{5}$ dret

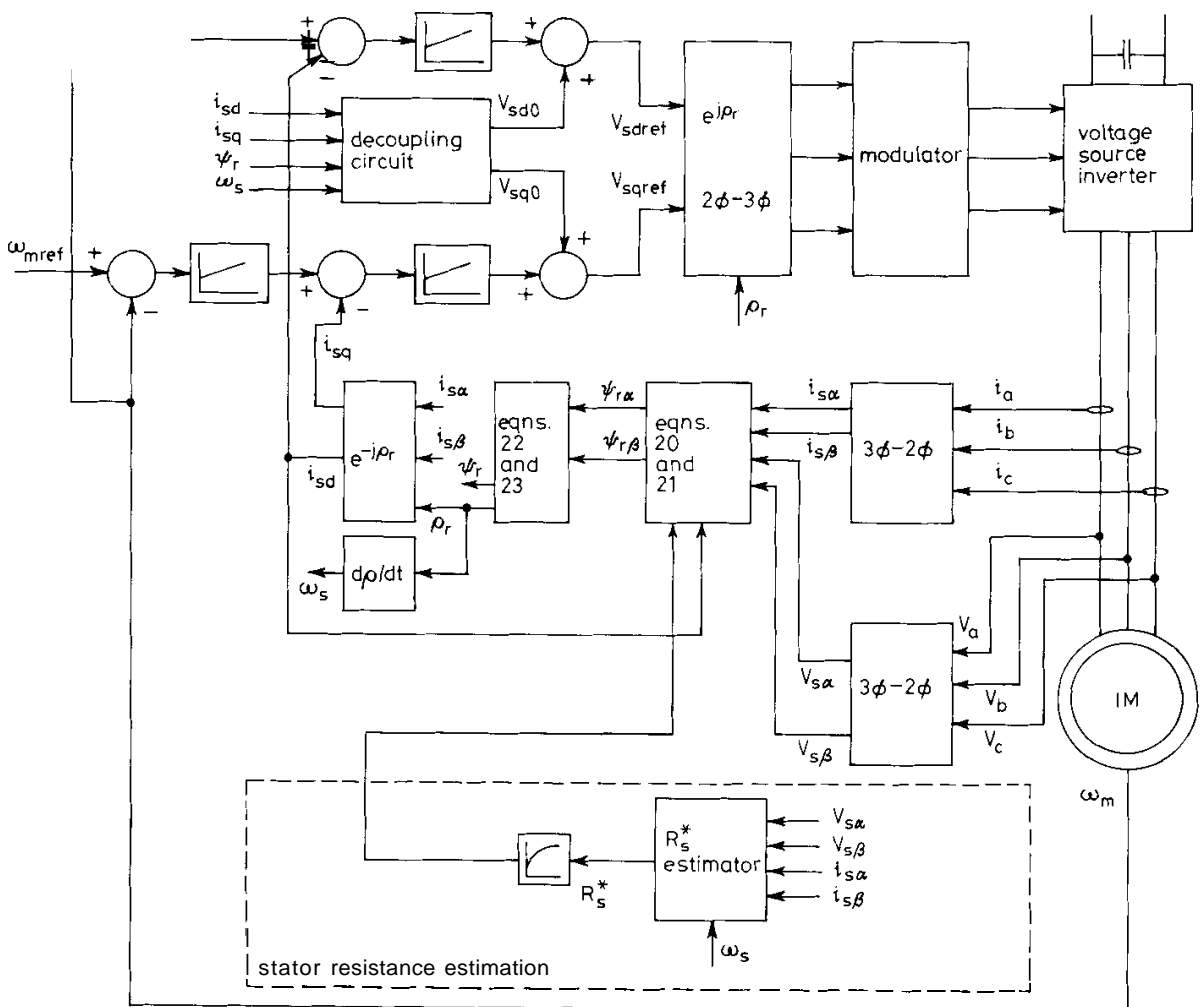

Fig. 3 Rotorfield-oriented speed conrrol with stator resistance estimation

shall be considered and the leakage inductances shall be assumed to be constants. Further, the stator and the rotor leakage inductances shall be considered equal. As a consequence

$$
L_{\sigma s}=L_{\sigma r}=L_{\sigma a}
$$

are constant with respect to variations in $M$ due to the saturation effect

$$
L_{\mathrm{ss}}=L_{\mathrm{rr}}=L_{a}
$$

From eqn. 36, the error in the stator flux due to variations in $M$ is given by

$$
\Delta \psi_{s}^{*}=\left(\frac{\Delta M}{\psi_{s}^{*}}\right)\left(\left(1+\frac{L_{\sigma a}^{2}}{L_{a}^{2}}\right) \frac{P_{r}}{\omega_{s}}-L_{\sigma a} i_{s}^{2}\right)
$$

and from eqn. 37. the error in the rotor flux due to variations in $M$ is given by

$$
\Delta \psi_{r}^{*}=\left(\frac{\Delta M}{\psi_{r}^{*}}\right)\left(\frac{P_{r}}{\omega_{s}}-L_{\sigma a} i_{s}^{2}\right)
$$

Using eqns. 32, 38 and 39, the error in the stator resistance estimate can be obtained as

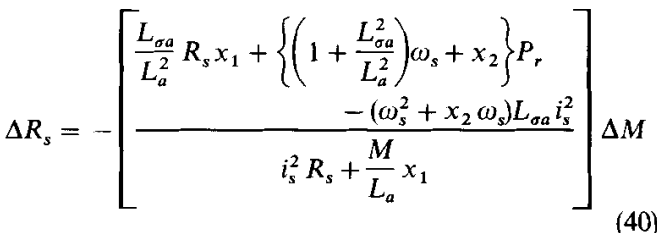

$$
\begin{array}{rl}
{ }^{\text {where }} & = \\
x_{1} & p i_{s q r}^{*} \omega_{s} \psi_{r}^{*} \\
x_{2} & =p\left(M / L_{a}\right) R_{s}\left(i_{s q r}^{*} / \psi_{r}^{*}\right)
\end{array}
$$

For a given load, the error in stator resistance varies linearly with the magnetising inductances $M$. The negative sign in eqn. 40 is owing to the fact that for an increase in $M$, the stator resistance estimate reduces correspondingly. A simulation result indicating the percentage error in the stator resistance to variations in the magnetising inductance at constant load torque is shown in Fig. 2. It 
is evident from Fig. 2 that for a given percentage change in $M$, the corresponding percentage error in the stator resistance estimate is considerably less.

\section{Implementation scheme}

The block diagram for a rotor field-oriented speed control of induction motor with stator resistance estimation is shown in Fig. 3. The scheme consists of the current control loop nested in the speed control loop. Individual controllers for the d-axis and the q-axis currents are used in the synchronous frame. To avoid crosscoupling between the $\mathrm{d}$ - and q-axes voltages, voltage decoupling equations are used to obtain good current control action [3]. The d-axis and the q-axis reference voltages $\boldsymbol{V}_{\text {sdref }}$ and $\boldsymbol{V}_{\text {sqref }}$ are transformed to the stationary (i.e. stator) reference frame by performing an axis rotation through $\boldsymbol{p}$. The two-phase voltage references in the stator reference frame are then transformed to threephase staor reference voltages. The three-phase stator reference voltages are fed to the modulator which is generally based on a pulse width modulation strategy like the sine-triangle comparison or the space vector modulation schemes. The modulator output drives the switches of the voltage source inverter.

The entire speed control system in Fig. 3 was simulated using SIMULINK. The modulator used in this system is based on the sine-triangle comparison pulse width modulation strategy $[10,11]$. A triangle frequency of $1 \mathrm{kHz}$ is used. Each inverter phase or half bridge has a comparator which is fed with the reference voltage for that phase, and the symmetrical triangular carrier wave of $1 \mathrm{kHz}$ is common to all three phases. The triangular carrier has a fixed amplitude and the output voltage control is achieved by variation of the sine wave amplitude of the reference phase voltages.

The induction motor used has the following specifications :

Three-phase, $400 \mathrm{Vac}, 50 \mathrm{~Hz}$, four-pole machine

$R_{\mathrm{s}}=0.19 \mathrm{ohms}$

$\mathbf{R}_{,}=0.125 \mathrm{ohms}$

$\mathbf{M}=36.9 \mathrm{mH}$

$L_{\mathrm{ss}}=38.51 \mathrm{mH}$

$L_{r r}=37.56 \mathrm{mH}$

nominal drive torque $=98 \mathrm{~N} / \mathrm{m}$

The proportional-integral controllers for the speed and the current loops have the structure shown in Fig. 4. The

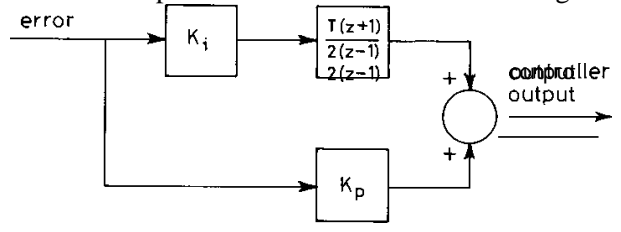

Fig. 4 Proportional-integral controller structure used in simulation

parameters of the controllers were found by minimising a quadratic cost function of the states and the inputs of the system. The parameters for the three loops are as follows: d-axis current loop:

Proportional gain $K_{p d}=0.655$

Integral gain $K_{i d}=108.339$

Sampling time $T=1 \mathrm{~ms}$

q-axis current loop:

Proportional gain $K_{p q}=0.8578$

Integral gain $K_{i q}=77.6506$

Sampling time $T=1 \mathrm{~ms}$
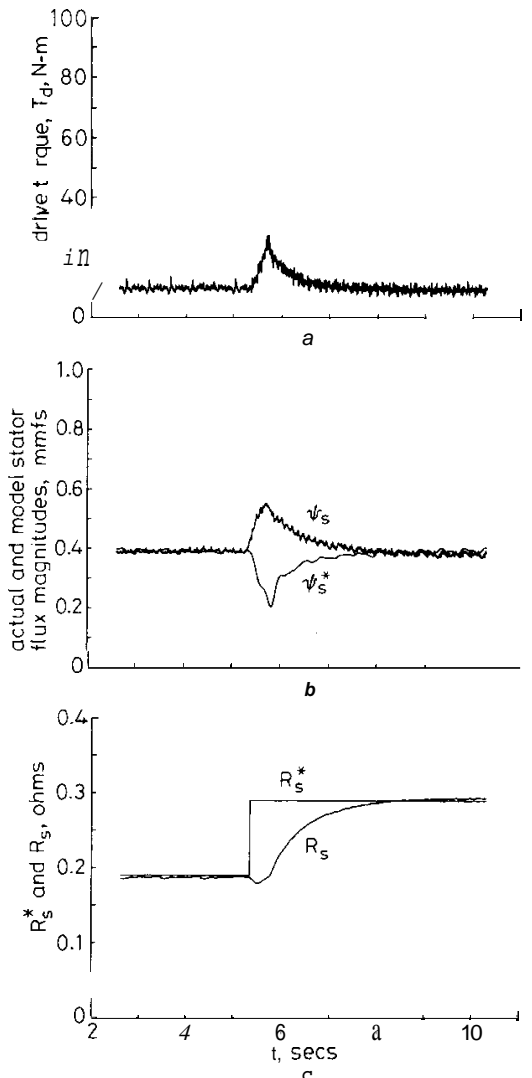

Fig. 5 Stator resistance estimation at $\omega_{m}=0 \mathrm{rad} / \mathrm{s}$ and $10 \%$ load a Drive torque $T_{d}$ $b$ Actual and model stator flux linkages $c$ Actual $\left(R_{*}^{*}\right)$ and estimated $(R$, values of the stator resistance

load torque, and Fig. 6 shows the results at zero rotor speed and $100 \%$ of the load torque, and Fig. 6 shows the results at zero rotor speed and $100 \%$ of the load torque. On application of a step change in the motor stator resistance, the motor demands extra torque to compensate for the loss in the increased stator resistance. A portion of the stored magnetic energy is used to supply the extra loss which results in the decrease of the actual flux. The stator currents increase to replenish the increased losses. As the actual flux decreases with a slower time constant compared to the time constant at which the stator currents increase, there is a momentary dip in the stator resistance estimate. When the resistance in the model is less than that in the motor, the increased stator currents build up the magnetic energy which results in an increase in the model flux. As the actual value of the flux builds up, the stator resistance estimator tracks the motor stator resistance.

A point to be noted is that the estimation of the stator resistance is valid under steady-state operation. As the rate of change in the stator resistance due to temperature 
is very low compared to the electrical time constants of the induction motor, the stator resistance estimator can be disabled during transient conditions. The quadrature axis current $i_{s q}$, or an estimate of the electromagnetic torque, gives the necessary information regarding the
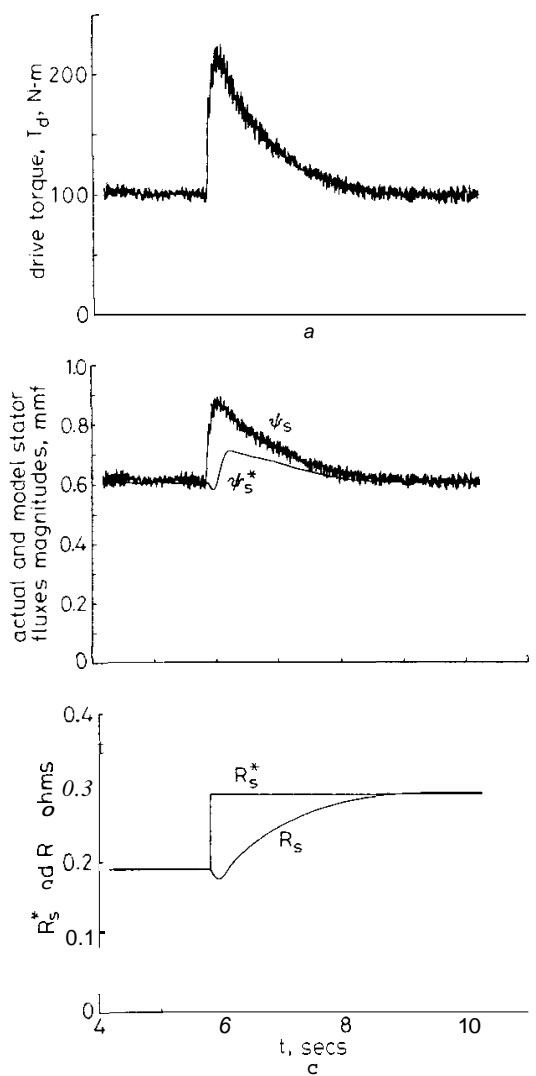

Fig. 6 Stator resistance estimation at $\omega_{m}=0 \mathrm{rad} / \mathrm{s}$ and $100 \%$ load $a$ Drive torque

del stator flux linkage

$c$ Actual $\left(R_{s}^{*}\right)$ and estimated $\left(R_{v}\right)$ values of the stator resistance transients during which time the stator resistance estimator can be disabled. An alternative solution would be to slow down the stator resistance estimation by passing it through a low pass filter.

\section{Conclusions}

In this paper, the problems in the flux estimation and control due to variations in the stator resistance of the induction motor were discussed. A method of estimating the actual value of the stator resistance from terminal variables alone was elucidated. The stator resistance estimation algorithm was demonstrated by simulating a rotor field-oriented speed control system.

\section{References}

I ABBONDANTI, A.: 'Method of flux control in induction motors driven by variable frequency, variable voltage supplies'. Proceedings of IEEE/LAS Int. Conf. on semiconductor power, March 1977, pp. 177-187

2 LEONHARD, W.: Control of electrical drives' (Springer Verlag 1985)

3 VAS, P.: 'Vector control of AC machines' (Clarendon Press, Oxford, 1990)

4 LORON, L.: 'Stator parameters influence on the field oriented control tuning', $E P E, \mathbf{1 9 9 3 , 5}$, pp. 79-84

5 WILLIAMS, B.W., and GREEN, T.C.: 'Steady-state control of an induction motor by estimation of stator flux magnitude', IEE Proc. $B, 1991,138,(2)$, pp. 69-74

6 VERGHESE, G.C., and SANDERS, S.R.: 'Observers for flux estimation in induction machines', IEEE Trans., 1988, IE-35, (I), pp 85-94

7 UMANAND, L.. and BHAT, S.R.: 'Shaft transducerless rotor field orientation in an induction motor with stator resistance adaption'. PCIM Intelligent motion June 1994, pp. 387-396

8 AKIN, E., ERTAN, H.B., and UCTUG, M.Y.: 'Vector control of induction motor through rotor flux orientation with stator flux components as reference'. Proceedinas of ICEM '92, Manchester UK, 1992, pp. 853-857

9 FRATTA, A., VAGATI, A., and VILLATA, F.: 'Vector control of induction motors without shaft transducers'. Proceedings of PESC '88, 1988, pp. 839-846

10 HOLTZ, J., and KHAMBADKONE, A.M.: 'Pulse width modulation for controlled AC motor drives'. EPE 93 tutorials, September 1993

11 STEMMLER, H., and GUGGENBACH, P.: 'Configurations of high power voltage source inverter drives'. Proceedings of EPE '93, 5, pp. 7-14 